\title{
DIFFERENTIAL DIAGNOSIS AND LIMITATIONS OF EXTERNAL SPHINCTEROTOMY
}

\author{
By A. Leriche, J. P. Archimbaud, E. Berard, P. Minaire and J. Bourret \\ H.C.L. Hôpital Henry Gabrielle, Route de Vourles, 69230 Saint-Genis-Laval, \\ Lyon, France
}

\begin{abstract}
A study of 1000 neurologic bladders has shown us that a well-balanced working of the bladder must be keenly searched for, and that sphincterotomy must be early indicated, and even performed several times if necessary.

So IOO sphincterotomies performed on male patients, out of 730 cases, have shown us that their one-and-only risk, incontinence, depended chiefly on the condition of the detrusor, therefore on the short or long evolution of the sclerosis of the external sphincter, which is only one out of all the possible impediments.
\end{abstract}

\section{The Effects of the Detrusor in the Neuro-Urinary Troubles}

THIS chiefly concerns lesions at low level with atonic bladders but with a normal abdominal musculature. The pressure of the bladder for voiding is very high indeed (for example, Ioo $\mathrm{mm}$. of mercury), but the patient still suffers from retention.

This patient (fig. I) finally went through an endourethral resection of his vesical neck, followed by external sphincterotomy, but without success, and he is still suffering from retention. What can we do, then? The ice-water test shows us that it is not a question of an atonic bladder, although cystometry has shown areflexia of the bladder. The detrusor contracts, the vesical neck and the external sphincter can open then after the test and there is a synergy (fig. 2).

How can we re-educate such a patient? We cannot do the same as with an automatic reflex bladder because percussing is insufficient on the detrusor which leads to a hypertonia of the external sphincter, as the electromyography can confirm it. Day after day we must perform some ice-water tests until the synergy between the detrusor and the external sphincter establishes itself. The patient, whose radiographs can be seen (fig. 2), can normally urinate until his bladder is quite empty, but he must wait for some kind of desire to pass urine. It sometimes happens that sphincterotomies are not successful, although the histological examination shows a sclerosis of the external sphincter. Such failures can be explained because the detrusor is not capable of contracting enuugh. Sometimes one has to wait, because the functional development may take rather a long time, and we found that some patients could get a well-balanced working of their bladders only after one year or so.

\section{The Troubles of the Statics of the Bladder}

It also concerns lesions at low level, with an insufficient detrusor generally, but with a good abdominal musculature. The urethrography sometimes shows a dilatation of the prostatic urethra and a stop at the level of the external sphincter. 


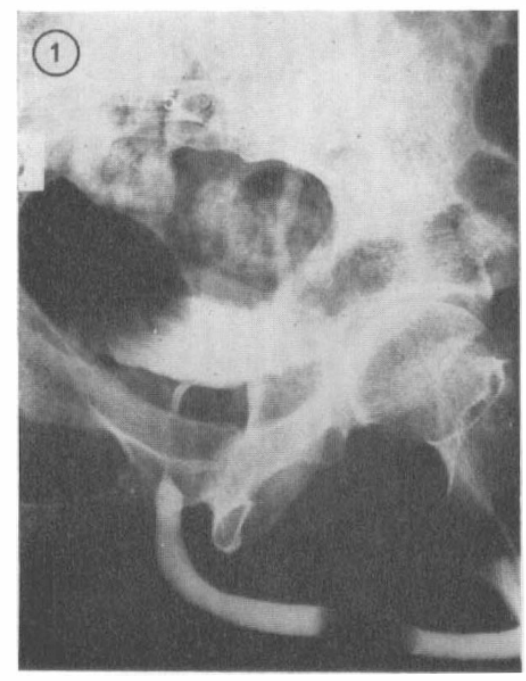

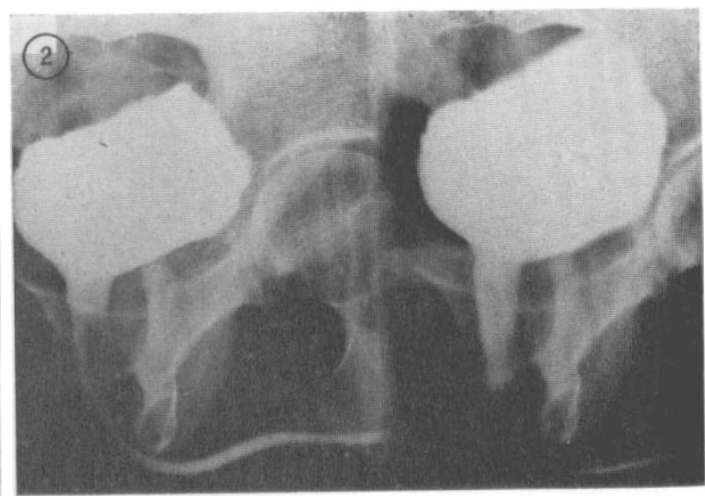

FIG. I

Bladder obstruction in low-level spinal cord lesion.

FIG. 2

The ice-water test showing the synergy between the detrusor, the neck and the external sphincter.

In fact, it may be a folding of the urethra caused by a rocking of the bladder, which we shall only be able to demonstrate after showing dynamic radiographs such as the one we have here. If we simultaneously perform an urethro-cystography and a barium enema, we can establish that there is also a rectal prolapse, showing lowering of the bladder at the level of the pelvic floor. The sclerosis of the external sphincter can exist, but its resection will not work out the urinary problem, and most of the time these patients have a persistent dysuria. Therefore, a colocystopexia is to be performed. In our series of 100 sphincterotomies, whenever there was an important dysuria, there was also troubles of the statics of the bladder in 50 per cent of the cases and sphincterotomy only was a failure.

\section{Spasticity of the Pelvic Floor}

Spasticity seems to act more effectively against micturition than the sclerosis of the external sphincter. Diagnosis can be established on the urethrogram in such cases too (fig. 3), and we insist upon the continuous harmony of the bends of the urethra and also upon the length of its frank and regular shrinking in order to determine spasticity of the pelvic floor at a time when the sclerosis of the external sphincter is revealed by an unregular stenosis of about I or $2 \mathrm{~cm}$. long.

Above the stenosis the damage is revealed just the same by radiographs, whether it is a sclerosis in the external sphincter or a hypertonia of the pelvic floor:

(i) No closing of the neck outside micturition time.

(ii) dilatation of the prostatic urethra until it finally looks like a radish.

(iii) A reflux into the spermatocysts.

(iv) Impregnation of the prostatic gland.

The hypertonia of the pelvic floor may hide a sclerosis of the external sphincter and there the pudendal infiltrations, that stop the spasms of the pelvic 

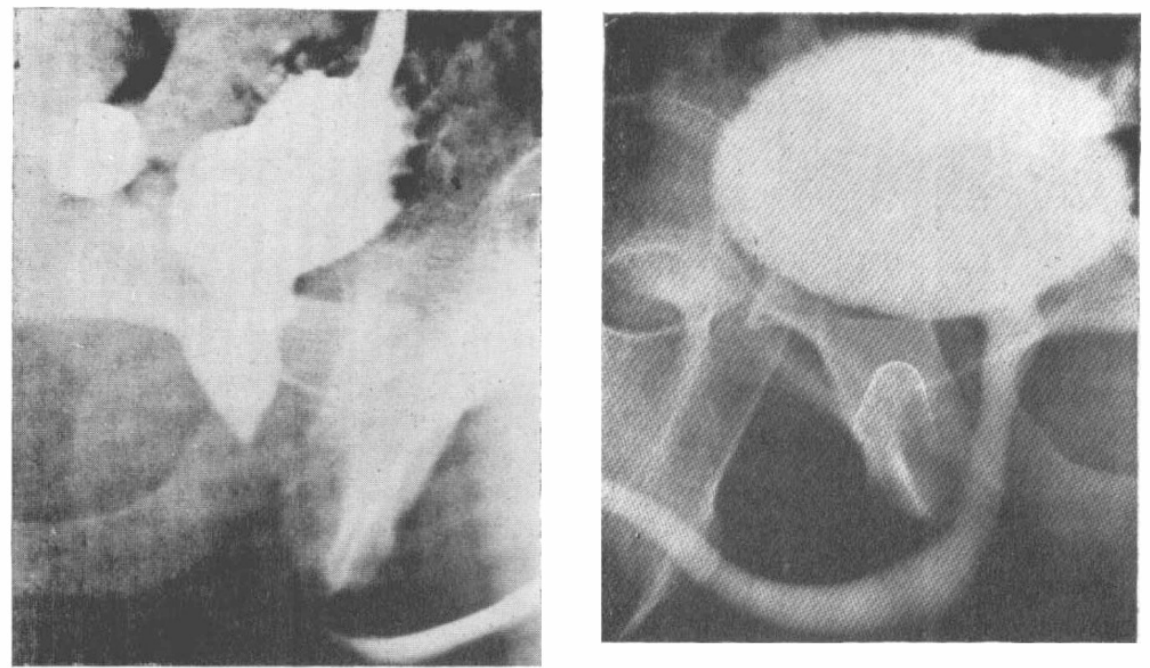

FIG. 3

Differential diagnosis with the spasticity of the pelvic floor before pudendal block.

FIG. 4

Micturition after pudendal block reveals disappearance of spasticity of the bladder.

floor, help to establish the diagnosis (fig. 4). In the series, counting Ioo sphincterotomies, 20 per cent of the patients have still suffered from urinary troubles, in spite of the resection of their sphincters, by the fact of the hypertonia of their pelvic floor (fig. 5). So, there is sometimes a bulging situated $\mathrm{I} \mathrm{cm}$. under the sphincter, which you can notice thus:

(i) A round shape on the urethrogram.

(ii) A maximum resistance compared with the rest of the urethra, on the sphincterometrogram.

(iii) And a kind of diaphragm, like the diaphragms in the cameras, thanks to the endoscopy (Leriche, I973).

There, one can find the best indication for an electromyography, which is only significant if it is made during micturition, or while the patient is percussing the suprapubic area (Chantraine, 1967; Markland, 1971). Within the framework of this hypertony of the pelvic floor the good effect of a peridural anaesthesia on the ureteral reflux is to be observed (fig. 5). Sometimes the reflux may even disappear for ever, even if it were two-sided (fig. 6, same patient) and therefore we perform such an examination more often now, first for the diagnosis, but also for the treatment. The peridural anaesthesia also lets us know the various degrees for a hypertonic detrusor to recover.

If the capacity of the bladder is increasing, the bladder is neither really sclerotic nor inflamed, and there exists a spastic element sufficient to make the detrusor retract. In such cases we can help the patient to improve his continence (fig. I) after we have performed a sphincterotomy thanks to anaesthesia, then 

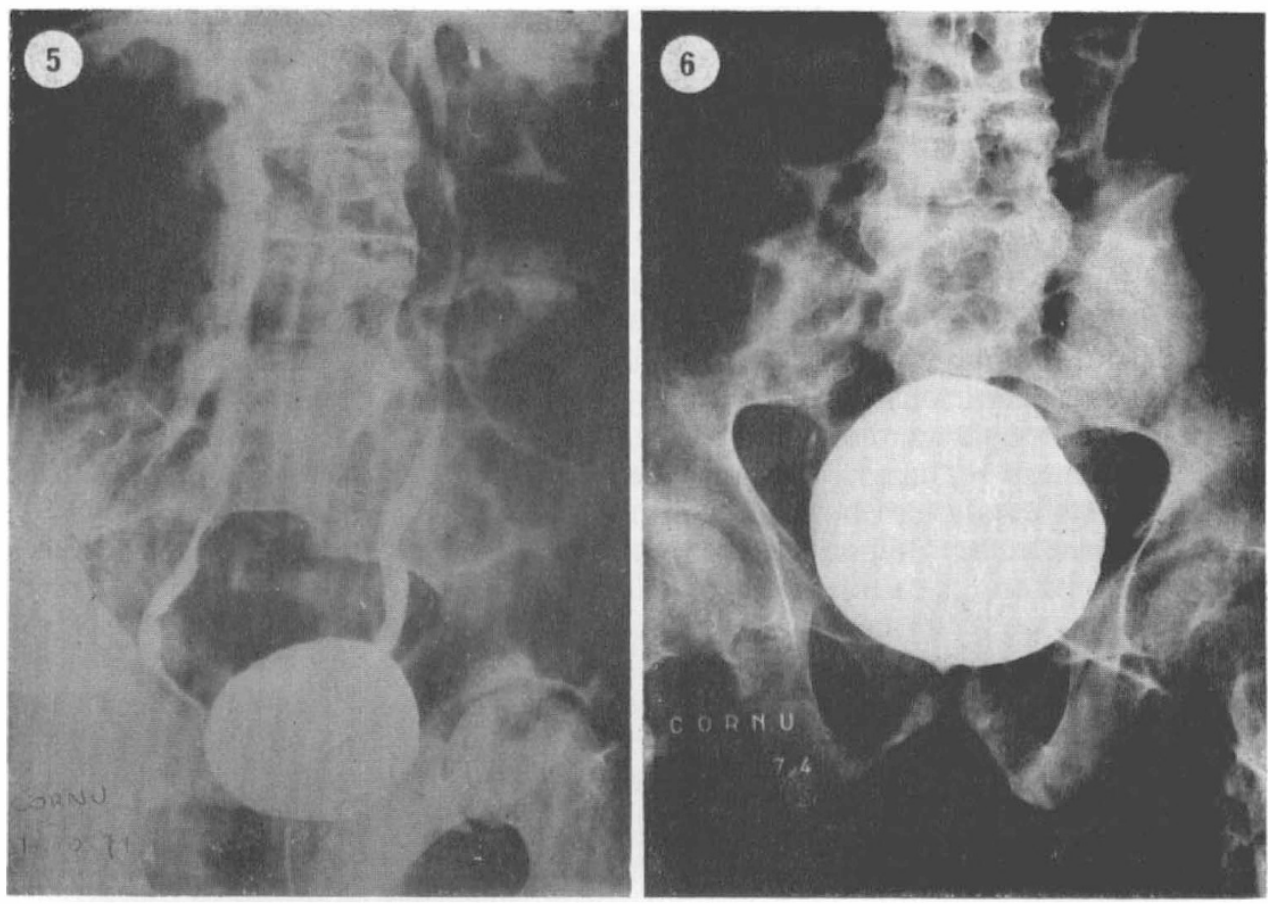

FIG. 5

Bilateral ureteral reflux due to spasticity of the pelvic floor before peridural anaesthesic.

FIG. 6

Reflux disappeared after peridural anesthesia.

selective alcoholisations of his sacral roots. If the patient is unable to recover his urinary working there is no use performing a sphincterotomy, because a urinary diversion will be imperative. Yet there are still some sphincterotomies performed now because of the psychological point of view, even if the need is no longer good, which will certainly not improve the statistics.

\section{Spasticity of the External Sphincter}

Such a spasticity exists as a premonitory symptom in 90 per cent of sclerosis of the external sphincter, but it will also be found in most spastic paraplegics although it doesn't cause urinary troubles. Sometimes, pudendal infiltration or infiltrations near the sphincter can stop that hypertony (Cukier, I963). We perform them in series, in the beginning of taking off the catheter in cases whenever the radiographs show a discontinuance at the level of the external sphincter (Ascoli, I967). Whenever the results are not successful, or not lasting, we then perform a sphincterotomy.

Histology has shown that some sphincters, although they react during the electromyography and pudendal infiltrations, often happened to be degenerate and 
sometimes sclerotic. Therefore, there is no use waiting for performing a sphincterotomy. That is the reason why, two years ago, we finally stopped the long series of pudendal infiltrations because they just delayed the sphincterotomy and also made the results worse. Within our series of Ioo sphincterotomies, the results were bad in I 5 per cent, and very good in 40 per cent when we had decided to delay the resection for one year in the hope that the pudendal infiltrations would be adequate to diminish the spasm of the external sphincter. On the other hand, the results were very good in 60 per cent of the cases, and bad in Io per cent, when sphincterotomy had immediately followed the diagnosis.

However, we must not be too radical, in fact, the radiological diagnosis of a sclerosis of the external sphincter does not lead automatically to a sphincterotomy (Ross, 1967). So, for some years, we have been watching about 20 cases of sclerosis of the external sphincter whose radiographs have not varied and whose bladders are well balanced. It is really essential to have a possibility of watching these patients regularly, because their upper urinary tract might get worse within a few months, and yet they will not be anxious about dribbling incontinence.

\section{Vesical Prostatism}

It appeared in 50 per cent of cases out of the series of Ioo sphincterotomies. We consider then the bulging of the vesical neck and the urethro-vesical acute angle during injection of urethrocystography. The vesical prostatism has only indicated a transurethral resection on 20 per cent of cases. Histology has always shown a non-inflammatory sclerosis.

Sometimes there may be a post-strictural dilatation of the prostatic urethra which may be combined with a sclerosis of the external sphincter. Such a diagnosis has for some time led to resections of the bladder neck. Even now, some urologists still proceed with various resections successively: bladder neck, prostate, and the external sphincter until this bladder can void well.

There are still indications for transurethral resections of the vesical neck. In fact a minimum resection, about a grain of rice long, is sometimes sufficient for perfect micturition, when the discontinuation of the catheter has been impossible. We must remember that the vesical neck really insures and supervises the continence, after external sphincterotomy had to be performed.

\section{Pathology of the Prostate and Urethral Stenosis}

Both are also impediments to micturition. Diagnosis is radiological, either by the means of the I.V.P. or by the means of the urethro-cystography. Nowadays, there are many old paraplegic patients in whom prostatic hypertrophy is common. That is the reason why a transurethral resection of the prostate had to be performed in three per cent in our series of 730 patients. Out of this series the urethral stenosis, especially post-traumatic, cover $\mathrm{I} \cdot 5$ per cent of cases. We have treated them either surgically or by means of dilatations.

\section{Special Problems in Female Patients}

The sclerosis of the external sphincter also exists in female patients although the radiological visualisation is rare because of the shortness of the urethra. 
In such cases we have to perform a sphincterotomy (Audic, I97I) with 'urethric profiles'. The main symptom consists in dribbling incontinence because the obstruction makes the detrusor react early. We then perform either an internal urethrotomy or urethral dilatations (Jeejeebhoy, I962).

\section{Conclusion}

A proper diagnosis is essential before the performance of sphincterotomy; if not, it is a failure, because of incorrect indications.

Thanks to the peridural anaesthesia, or to selective alcoholisations of sacral roots, we can get a better continence because it allows a recovering of the bladder. Such methods can make some reflux disappear.

Frequent use of the ice-water test allows recovery of the synergy between the contraction of the detrusor and the opening of the external sphincter.

Thanks to a kinetic study of micturition we have found some troubles of the static of the bladder associated with sclerosis of the external sphincter. Such disturbances need surgical treatment, otherwise retention and dysuria will still be present in spite of sphincterotomy.

\section{RÉSUMÉ}

A propos de 100 cas de résection du sphincter externe chez l'homme paraplégique. Les auteurs tentent de définir les limites de la sphinctérotomie en replaçant la sclérose du strié dans le cadre de la neuro pathologie urinaire du paraplégique: troubles de la statique vésicale (intérêt de la colocystopexie), spasticité du strié et du périnée, maladie du col, pathologie prostatique et sténose uréthrale. Entre autres méthodes de diagnostic le test à l'eau glacée leur parait d'autant plus intéressant qu'il peut se concevoir comme une technique de rééducation.

\section{ZUSAMMENFASSUNG}

Die Autoren beschreiben die Grenzen der Sphinkterotomie bei Ioo Patienten mit Querschnittslähmungen. Unter den disgnostischen Methoden hat sich der Eiswasser-Test als wertvoll erwiesen als eine Technik zur Wiederherstellung der Blasenfunktion.

\section{REFERENCES}

Ascoli, R. R. (1967). Radiological study of the vesical neck in paraplegia, secondary to spinal cord injury. Paraplegia, 4, 235-240.

Audic, B. (I970). Obstructions neurogènes du bas appareil urinaire chez l'enfant. Table ronde. f. Urol. Néphrol. 76, $219-224$.

Chantraine, A. \& Timmermans, L. (1967). Electromyography in spinal cord lesion with special reference to the sphincter. Paraplegia, 4, 240-244.

Cukier, J., Maury, M., Audic, B. \& Baccialone, L. (I963). La miction dans les lésions médullaires complètes et ses dysfonctions. Ann. Méd. Phys. VI, 3, I63-190.

JeEJEEBHOY, H. A. (I962). A new approach to the management of the spastic external sphincter. F. of Urol. (Baltimore), 88, 507-510.

Leriche, A. (1973). M.D. Thesis, Lyon, Ediprimedit.

Markland, C., Bradley, W., Chou, S., Merrill, D. \& Westgate, H. (I97I). Sacral nerve stimulation. A diagnosis test of bladder innervation. British fournal of Urology, 43, 453-459.

Ross, J. C., Gibbon, N. O. K. \& Damanski, M. (1967). Division of the external sphincter in the treatment of the neurogenic bladder. A ten year review. British fournal of Surgery, 54, 627-628. 